\title{
Older adolescents discussed sexual behaviour with partners after trust had been built
}

Lock SE, Ferguson SL, Wise C. Communication of sexual risk behavior among late adolescents. West J Nurs Res 1998 Jun;20:273-94.

\section{Question}

How do older adolescents perceive communication with their partners about sexual risk behaviour (multiple partners; sexual intercourse without condoms; or sexual intercourse with partners who have HIV infection, have a sexually transmitted disease [STD], or who use or have used intravenous drugs)?

\section{Design}

Grounded theory.

\section{Setting}

A public university in south east US.

\section{Participants}

32 single adolescents (mean age 19 y, $56 \%$ women, $72 \%$ white, and mean age at first intercourse $17 \mathrm{y}$ ) who had never been pregnant or fathered a child and had had sexual intercourse.

\section{Methods}

A semistructured interview by a researcher of the same sex dealt with perceptions of decisions to have sexual intercourse and discussions with partners about birth control, previous sexual partners, STDs, and intravenous drug use. Interviews were analysed separately for men and women using constant comparative analysis.

\section{Main findings}

Building trust was the core variable (fig). Both men and women were more comfortable talking about sexual risk behaviour when they trusted their partners. Women built trust by gathering information indirectly about potential sexual partners, and men used their instincts and assessed external factors. After trust was established, women felt that they could initiate discussions on sexual risk behaviour, and men felt that they were willing to take part in discussions. Women felt that open discussions were easier if alcohol was not used; if they had previous sexual experience and a good knowledge base about reproduction, contraception, and sexual risk behaviour; if they had discussed similar topics with their friends; or if the media had provided the motivation to discuss sexual risk related topics. Men and women felt trust had to be shown repeatedly. Despite safe sex talk, many participants showed trust in their partners by engaging in unsafe sexual practices.

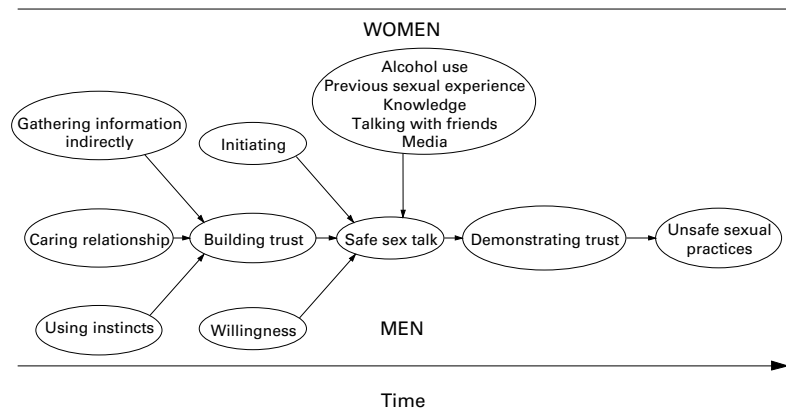

Figure reprinted by permission of Sage Publications from: Lock SE. Communication of sexual risk behaviour among late adolescents. Western Journal of Nursing Research 1998;20:273-94.

\section{Conclusions}

Older adolescents felt willing and able to discuss sexual risk behaviour in a stable relationship after trust had been established. Discussion did not guarantee safe sexual behaviour.

Source of funding: American Nurses Foundation.

For correspondence: Dr S E Lock, College of Nursing, University of Kentucky, 435a Health Sciences Learning Center 0232, Lexington, KY 40536-0232, USA. Fax +1 6063231057.

\section{Commentary}

Lock et al provide an interesting new model of communication of sexual risk behaviour among adolescent partners. Most participants used condoms during last intercourse and seemed to be knowledgeable and generally conscientious about safe sex practices.

What is particularly useful about this model is that it shows the differences in the way young men and women approach communication with potential sexual partners about safe sex practices. Although both agreed that a caring relationship was needed to build confidence that the potential sexual partner was being truthful about sexual history, women were more likely to initiate a conversation about safe sex and to identify circumstances that influenced such talks. Women were frustrated with having to initiate discussions and were discouraged when the partner either did not continue the discussion or became angry. This suggests that young women carry a heavy burden for protecting themselves and could benefit from learning assertive strategies.

Among women, the findings that alcohol clouds judgment, and that previous sexual experience, knowledge about sexual issues, social support, and messages from the media increased their likelihood of engaging in safe sex discussions should form the basis for safe sex interventions. We do not know how such interventions might influence the communication behaviours of men.

A recent US publication focuses on topics in sexuality education that are difficult to teach such as negotiating safer sex. ${ }^{1}$ Teachers admit that they do not know how to encourage young adolescents to assess their sexual risk, set limits, and avoid mixing alcohol and drugs with sexual activity. If further research shows that this model is also applicable to the young teen, it can provide direction to nurses, other professionals, and parents to develop and test more effective strategies of safe sex negotiation.

\footnotetext{
Lynn Rew, RN, EdD

Associate Professor and Graduate Advisor School of Nursing

University of Texas at Austin Austin, Texas, USA

1 SIECUS. Filling the gaps: hard to teach topics in sexuality education. New York: Sexuality Information and Education Council of the United States, 1998.
} 